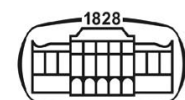

AKADÉMIAI KIADÓ

Acta Microbiologica et

Immunologica Hungarica

67 (2020) 1, 1-5

DOI: 10.1556/030.66.2019.031

(c) 2019 Akadémiai Kiadó, Budapest

\title{
Provocation of life functions at a unicellular eukaryote level by extremely low doses of mammalian hormones: Evidences of hormesis
}

\section{GYÖRGY CSABA*}

Department of Genetics, Cell- and Immunobiology, Semmelweis University, Budapest, Hungary

Received: April 08, 2019 • Accepted: May 15, 2019 • Published online : December 09, 2019

\section{ORIGINAL ARTICLE}

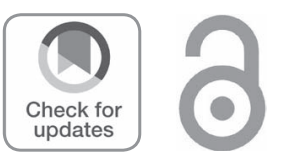

* Corresponding address: György Csaba

Department of Genetics, Cell- and Immunobiology, Semmelweis University, Nagyvárad tér 4, POB 370, 1445 Budapest, Hungary Phone/Fax: +361210 2950 E-mail: csaba.gyorgy@med. semmelweis-univ.hu

\begin{abstract}
Hormones, characteristic to higher ranked animals, are synthesized, stored, and secreted by unicellular eukaryote animals. The unicells also have receptors for recognizing these materials and transmit the message into the cells for provoking response. The hormones are effective in very low concentrations (down to 10-21 M) and opposite effects of lower and higher concentrations can be observed. However, sometimes linear concentration effects can be found, which means that hormesis exists, nevertheless uncertain, as it is in the phase of formation (evolutionary experimentation). Hormesis, by transformation (fixation) of cytoplasmic receptor-like membrane components to receptors in the presence of the given hormone, likely helps the development of unicellular endocrine character and by this the evolution of endocrine system. The effect by extremely low concentrations of hormones had been forced by the watery way of unicellular life, which could establish the physiological concentrations of hormones in the blood of higher ranked animals. This means that hormetic low doses are the normal, effective concentrations and the high concentrations are artificial, consequently could be dangerous.
\end{abstract}

\section{KEYWORDS}

Tetrahymena, evolution, hormone receptors, hormesis, protozoa

\section{INTRODUCTION}

Classically interpreting, a hormone is a molecule secreted by endocrine glands, transported by the blood circulation and evokes response in a specific target organ [1]. Later, the definition "endocrine glands" has been modified to endocrine cells, as many hormone-producing units are not organ-like entities; blood circulation has been modified to some fluid, or has been omitted, considering the case of paracrine effects, and the "specific target organ" has been changed to target cells, which can be anywhere in an organism (e.g., embedded into cell mass with other specificity). It was also cleared that hormones and endocrine system can be present not only in mammals and vertebrates, but just at unicellular eukaryote level and hormones characteristic to mammals are produced and effective also at a unicellular level [2-6]. Considering the organ systems of mammals (men), perhaps the most essential differences in the attitude of organ systems happened in the case of the neuroendocrine system and hormones. A lot of new, non-glandular hormones have been observed, declared to hormones, and inserted into the thesaurus of neuroendocrine system; in addition, the new hormones could have therapeutic use. It was cleared that molecules recorded earlier in another category, e.g., vitamins (vitamins A and D) are hormones [7] and many sexual-hormone-like molecules appeared in the environment (and are effecting in the mammalian organisms) as hormonelike endocrine disruptors [8]. The mentioned facts resulted in the simplest definition [9] of a

This is an open-access article distributed under the terms of the Creative Commons Attribution 4.0 International License, which permits unrestricted use, distribution, and reproduction in any medium, provided the original author and source are credited, a link to the CC License is provided, and changes - if any - are indicated. (SID_1) 
hormone: it is an intercellular messenger, and considering this, it could be present in the unicellular world and started from this level they have an important role as mediators of evolutionary phenomena [10].

In this review, the synthesis (production) of hormones characteristic to mammals and the role of their very low concentrations at a unicellular eukaryote level are presented and discussed [11-14]. In addition, the machinery, which is needed for their hormone production as well as for the hormone reception, is introduced $[15,16]$. The unicellular ciliate, Tetrahymena, is a suitable model for demonstrating the new facts; however, other unicellulars are also included in them.

\section{FACTS}

\section{On hormones in unicellulars}

Unicellular eukaryotes synthesize hormones, characteristic to higher ranked animals [2, 5]. Tetrahymena pyriformis, Neurospora crassa, and Aspergillus fumigatus contain (produce) substances, similar to mammalian insulins [5]. T. pyriformis also synthesizes neurotransmitters [17] and paramecium synthesizes atrial natriuretic peptide [18, 19]. In addition, $T$. pyriformis synthesizes steroid hormones, as dehydroepiandrosterone (DHEA), DHEA sulfate, testosterone, and estradiol $[20,21]$. The presence of sex hormones was demonstrated also earlier [22]. Trypanosoma cruzi and Tetrahymena synthesize melatonin $[23,24]$ and unicellulars in general produce opiates [15]. The unicellulars also have receptors for these hormones and are activated by them. The receptors, which are not present (e.g., steroid hormone receptors), can be developed by the presence of the target hormone. In addition, the presence of the target hormone provokes hormonal imprinting [25-28], which usually enhances the reaction capability of the cells to further presence of the given hormone.

\section{On hormesis in case of unicellulars}

Biogenic amines (serotonin and catecholamines) stimulate the phagocytic capacity of Tetrahymena thermophila [29] at 0.1-1.0 $\mu \mathrm{M}$ concentrations (optimal concentrations). Histamine and serotonin contents of $T$. pyriformis were studied under the effects of the same hormones and insulin in different concentrations between 10-6 and 10-21 M, for $30 \mathrm{~min}$ [30]. Histamine at the higher ranges elevated the serotonin content, whereas serotonin in the lower ranges (down to 10-21 M) decreased its histamine level. Insulin between 10-6 and 10-21 M increased the histamine level. Histamine influenced the insulin level only in 10-6 M concentration. Insulin did not affect the serotonin content at all, whereas serotonin increased the insulin level at each concentration studied. The effect of these hormones, including endorphin, gonadotropin, oxytocin, and epidermal growth factor (EGF), was also studied for the insulin binding of T. pyriformis in femtomolar (10-15 $\mathrm{M}$ or $0.001 \mathrm{IU}$ concentrations) and it was found that six of the seven hormones promptly decreased the hormone-binding capacity except EGF, and in cases of endorphin, serotonin, insulin, and oxytocin, the reduction was enormous [31]. The effect of six hormones (histamine, serotonin, insulin, EGF, oxytocin, and gonadotropin) was studied on the histamine, serotonin, adrenocorticotropin (ACTH), endorphin, and triiodothyronine synthesis (content) of T. pyriformis in 10-9 and 10-12 $\mathrm{M}$ concentrations or 0.1 and $0.001 \mathrm{IU} / \mathrm{ml}$. These picomolar concentrations, which can also be present in natural conditions, influenced the amount of other hormones inside the cells. Insulin was the only hormone, which influenced the concentration of other hormones in one direction, elevating them, whereas the others behaved individually and there were situations in which the two concentrations behaved in opposite direction [32]. Fluorescein isothiocyanateinsulin binding by $T$. pyriformis was studied in the presence of insulin, endorphin, serotonin, or histamine at 10-6 to 10-21 $\mathrm{M}$ and endorphin, serotonin, and insulin reduced the hormone binding down to 10-18 $\mathrm{M}$ [33].

When the imprinting effect of insulin and serotonin was studied to five parameters (insulin binding, insulin synthesis, swimming behavior, cell growth, and chemotaxis) of Tetrahymena in the long run, 10-15 $\mathrm{M}$ imprinter concentration was as effective as 10-6 M. [34].

Tetrahymena populations were treated with $10-15$ or 10-6 $\mathrm{g} / \mathrm{ml}$ concanavalin A (which is bound by insulin receptors) and the cells' ACTH, histamine, serotonin, endorphin, and triiodothyronine contents were measured. The extremely low concentration of ConA rather elevated the hormone contents than the higher dose [35].

In T. pyriformis, phagocytosis is stimulated by minute doses of many hormones and endocrine disruptors and there is not individual-specific reaction [36]. However, low concentrations of histamine are stimulating phagocytosis, whereas high concentrations decrease it [37]. In T. thermophila, the ciliary regeneration was stimulated by micromolar concentrations of serotonin and catecholamines, whereas millimolar concentrations had little effect or was ineffective [38]. Phagocytosis in T. thermophila is inhibited by nanomolar concentrations of opiates [39]. Atrial natriuretic peptide influences cell division in T. pyriformis with a positive effect in 10-12 M concentration [19].

Considering chemotactic effects of steroid hormones, testosterone is chemoattractant in a wide range of concentrations, whereas progesterone and dexamethasone are found only in two concentrations $(10-5$ or $10-6 \mathrm{mg} / \mathrm{ml})$. Hydrocortisone and estradiol were chemorepellent in each concentration [40].

Growth-promoting activity in $T$. pyriformis is concentration-dependent in case of insulin and histamine [41]. Insulin elevated cell count in each concentration; however, histamine at $10-5 \mathrm{M}$ concentration elevated, at 10-6 M concentration was neutral, and at 10-7 M concentration diminished cell count [41].

Diiodotyrosine treatment of $T$. pyriformis is effective between 10-9 and 10-15 $\mathrm{M}$ concentrations, but ineffective at 10-18 M. However, this latter dose executes imprinting, which can be observed 1, 2, and 4 weeks later [42]. 


\section{DISCUSSION}

There are some opinions that hormetic processes are observable at prokaryotic level [4]; however, the data are not convincing. Nevertheless, the facts unanimously show that hormesis is working also at a unicellular eukaryote level. This call attention that (1) hormesis is an ancient phenomenon and (2) it can be basically observed at a cellular and not only in organ and organismic level, although experiments in in vitro (tissue culture) conditions are extraordinarily low. It seems likely that the effects in very low concentrations had been enforced by the watery milieu, where these unicellular eukaryotes are living and in which the concentrations of active ingredients must be extremely low, considering their dissolutions.

As hormesis in higher phylogenetic levels seems to be a general principle (as it is shown also by chemotaxis experiments), when the biphasic effect was independent of both target tissue and chemoattractant agent [43] at unicellular level, there is some uncertainty. Although in most cases mentioned in "Facts," the stronger effect of lower concentration of hormones is more effective and there are some exceptions, when the linear principle is valid. This is understandable, if the elementary character of the process in this case is taking into consideration and this also points to the evolution of hormesis from the trial to the certitude (generalization).

It is very difficult to declare that certain materials are harmful or beneficial in case of unicellulars; however, these notions are not decisive from the aspect of hormesis [44]. Nevertheless, the biphasic dose responses to the hormonelike materials, which can be observed in higher ranked animals [45, 46], occur also in Tetrahymena.

According to Andersen and Barton [47], "both switching and homeostasis are regulated by controlling concentrations of hormone-receptor complexes" and it seems to be likely that this is also valid in the case of unicellular level, so highly nonlinear dose-response curves can be observed. Among the facts was shown some examples on the opposite effect of low and high hormone concentrations, which is a basic element of hormesis in mammals (men). This could mean that the effects of hormesis are similar both at unicellular and multicellular levels and some of these effects have a defending role during phylogeny, from the beginning, when the hormetic doses played the main role and this was (and it is) natural.

At a unicellular level, there are hormones (signal molecules) and receptors (receivers) as products of the unicell $[3,12]$; however, there is not a real (mammalian-like) endocrine system, as hormones find the receivers by chance, without a gene-controlled conciliation. There are also not data on feedback mechanisms, which are important for the endocrine system. These problems are only theoretical and are solved during the evolution. However, the changes during evolution could also alter the effects of hormesis in different phases of the process. This can change the details $[16,48]$, but the basic process is similar and it settles the hormesis into an evolutionary frame [49].
It can be supposed that there is no evolution without stress effects. However, it is very difficult to survive crude stress in case of unicellulars and this is right in the event of the hormonal system $[50,51]$. Hormesis helps to develop a training of unicells to later stress effects. As stress (e.g., higher salt concentrations, alcohol, and formaldehyde treatment) can alter hormone synthesis of unicellulars [52], the meeting with the low concentrations trains the cells and helps their survival.

The unicells have hormone receptors, which are similar (at least in Tetrahymena) to the membrane hormone receptors of higher ranked animals [53] and the effect of hormones through these receptors can help the life of Tetrahymena in endangered conditions $[54,55]$. Other investigations made likely that membrane-located hormone is the binding site for a hormone, insulin [56,57]. This means that an evolutionary experimentation is taking place, which leads to the receptor formation at a unicellular level [6]. According to Koch et al. [58], there is a continuous exchange between the cytoplasmic and membrane components, which, in case of the presence of the hormone, could be fixed in the membrane, as receptor $[50,58,59]$. In addition, there are receptors, which can be found intracellularly (e.g., inside the nucleus) and in the plasma membrane alike, having the same structure and binding capacity. This is characteristic to the steroid receptors; however, these receptors activate a fast response in the plasma membrane, whereas they activate prolonged response in the nucleus $[60,61]$. These processes could help the usefulness of hormesis at this low level of evolution and could give the basis for later hormetic phenomena.

For evolution, for the taking the necessary step into the next phase, time is needed and at least suboptimal conditions for life. Hormesis helps the endurance of noxious stresses and trains the cells to tolerate; otherwise, it results in unbearable stresses. In addition, at the unicellular level, the cells are not equipped with more complicated tools for survival, so hormesis seems to be the most suitable tool for helping the survival and evolution $[62,63]$. Genes are selected by meeting with hormetic doses to direct synthesis of proteins against stress (heat-shock proteins, antioxidant enzymes, and antiapoptotic proteins) or influence behavioral responses to environmental stressors.

Unicellulars (Tetrahymena) show the general adaptation syndrome, which was the basis of stress theory by Selye $[64,65]$, giving a general response to stressors [66-68]. It seems to be likely that hormetic effects can influence the process and this could have a role in the evolutionary adaptation to toxic impacts [69]. The existence and functions of mammalian (human) endocrine system can be deduced to a unicellular level, and hormesis also can be found in this study; this means that hormetic effects could be contributed to the formation of the present-time mammalian endocrine system.

As it was mentioned, unicells are living in a watery milieu, the high dissolution of materials is produced by them and this could force the enhancement of receptor sensitivity and the positive effect of very low doses. This could remain also in case of higher ranked animals as physiological concentration. The use of high doses artificial, however, as these were used 
in experiments and human therapy, classified the molecules, and their opposite effects in low concentrations have been surprising. If their classification would have been inverse, according to the effects of low doses, the opposite effects of high doses would not be unexpected [70].

Conflict of Interest: The authors declare no conflict of interest.

\section{REFERENCES}

1. Kaltenbach, J. C.: Endocrine aspects of homeostasis. Amer Zool 28, 761-773 (1988).

2. Bückmann, D.: Common origin and phylogenetic diversification of animal hormonal systems. Experienta Suppl 53, 155-166 (1987).

3. Roth, F., Leroith, D., Colier, E. S., Watkinson, A., Lesniak, M. A.: The evolutionary origins of intercellular communication and the Maginot Lines of the mind. Ann N Y Acad Sci 463, 1-11 (1986).

4. Pertseva, M.: The evolution of hormonal signalling system. Comp Biochem Physiol A Comp Physiol 100, 775-787 (1991).

5. Le Roith, D., Shiloach, J., Roth, J., Lesniak, M. A.: Evolutionary origins of vertebrate hormones: Substances similar to mammalian insulins are native to unicellular eukaryotes. Proc Natl Acad Sci U S A 77, 6184-6188 (1980).

6. Niall, H. D.: The evolution of peptide hormones. Annu Rev Physiol 44, 615-624 (1982).

7. Csaba, G.: Vitamin-caused faulty perinatal hormonal imprinting and its consequences in adult age. Physiol Int 104, 217-225 (2017).

8. Crews, D., McLachlan, J. A.: Epigenetics, evolution, endocrine disruption, health and disease. Endocrinology 147, S4-S10 (2006).

9. Chrousos, G. P.: Organization and integration of the endocrine system. Sleep Med Clin 2, 125-145 (2007).

10. Cox, R. M., McGlothlin, J. W., Bonier, F.: Evolutionary endocrinology: Hormones as mediators of evolutionary phenomena. Integr Comp Biol 56, 121-125 (2016).

11. Csaba, G.: Biogenic amines at a low level of evolution: Production, functions and regulation in the unicellulat Tetrahymena. Acta Microbiol Immunol Hung 62, 93-108 (2015).

12. Csaba, G.: The hormonal system of the unicellular Tetrahymena: A review with evolutionary aspects. Acta Microbiol Immunol Hung 59, 131-156 (2012).

13. Shpakov, A. O., Pertseva, M. N.: Signaling systems of lower eukaryotes and their evolution. Int Rev Cell Mol Biol 269, 151-282 (2008).

14. Shpakov, A. O., Derkach, K. V., Uspenskaia, Z. I., Pertseva, M. N.: Regulation by cyclic adenosine monophosphate of functional activity of adenylyl cyclase system of the infusorian Dileptus anser. Zh Evol Biokhim Fiziol 46, 119-125 (2010).

15. Harrison, L. M., Kastin, A. J., Weber, J. T., Banks, W. A., Hurley, D. L., Zadina, J. E.: The opiate system in invertebrates. Peptides 15, 1309-1329 (1994).

16. Derkach, K. V., Shpakov, A. O., Kuznetsova, L. A., Plesneva, S. A., Uspenskaia, Z. I., Pertseva, M. N.: The hormone-sensitive adanylyl cyclase system of the ciliate Dileptus anser. Tsitologia 44, 1129-1133 (2002).

17. Tziakouri, A., Lajkó, E., Köhidai, L.: The phylogenetic background of neurotransmitters in the unicellular organism Tetrahymena pyriformis. Ann Behav Neurosci 1, 108-118 (2018).

18. Vesely, D. L., Giordano, A. T.: Atrial natriuretic factor-like peptide and its prohormone within single cell organism. Peptides 13, 177-182 (1992).

19. Kőhidai, L., Csaba, G., Karsa, J.: Effects of natriuretic peptide on the unicallular Tetrahymena pyriformis model. Microbios 82, 27-40 (1995).

20. Levine, R.: Insulin action: 1948-80. Diabetes 4, 38-44 (1981).

21. Csaba, G., Inczefi-Gonda, Á., Fehér, T.: Induction of steroid binding sites (receptors) and presence of steroid hormones in the unicellular Tetrahymena pyriformis. Comp Biochem Physiol A Comp Physiol 82, 567-570 (1985).

22. Sonneborn, T. M.: Sex hormones in unicellular organisms. Cold Spring Harb Symp Quant Biol 10, 11-125 (1942).

23. Hardeland, R.: Melatonin and 5-methoxytryptamine in nonmetazoans. Reprod Nutr Dev 39, 399-408 (1999).

24. Macias, M., Rodrigueez-Cabezas, R., Reiter, R. J., Osuna, A., Acuna-Castravejo, D.: Presence and effects of melatonin in Trypanosoma cruzi. J Pin Res 27 (2007).

25. Csaba, G., Németh, G.: Enhancement of the sensitivity of Tetrahymena to a second hormonal influence by hormone pretreatment. Acta Biol Med Ger 39, 1027-1030 (1980).

26. Csaba, G.: Hormonal imprinting in the unicellular Tetrahymena: The protomodel of epigenetics. Acta Microbiol Immunol Hung 59, 291-310 (2012).

27. Csaba, G., Kovács, P.: Insulin treatment (hormonal imprinting) increases the insulin production of the unicellular Tetrahymena long term. Is there a simultaneous formation of hormone receptor and hormone? Cell Biol Int 19, 1011-1014 (1995).

28. Kőhidai, L., Vakkuri, O., Keresztesi, M., Leppaluoto, J., Csaba, G.: Induction of melatonin synthesis in Tetrahymena pyriformis by hormonal imprinting-a unicellular "factory" of the indoleamine. Cell Mol Biol (Noisy-le-grand) 49, 521-524 (2003).

29. Quinones-Maldonado, V., Renaud, F. L.: Effect of biogenic amines on phagocytosis in Tetrahymena thermophila. J Protozool 34, 435-438 (1987).

30. Csaba, G., Kovács, P., Pállinger, É.: How does the unicellular Tetrahymena utilise the hormones that it produces? Paying a visit to the realm of atto-and zeptomolar concentrations. Cell Tissue Res 327, 199-203 (2007).

31. Csaba, G., Kovács, P., Pállinger, É.: Effect of femtomolar concentrations of hormones on insulin binding by Tetrahymena, as a function of time. Cell Biochem Function 26, 205-209 (2008).

32. Csaba, G., Pállinger, É.: Is there a hormonal network in Tetrahymena? A systematic investigation of hormonal effects on the hormone content. Cell Biochem Funct 26, 303-308 (2008).

33. Csaba, G., Kovács, P., Tóthfalusi, L., Pállinger, É.: Effects of extremely low concentrations of hormones on the insulin binding of Tetrahymena. Cell Biol Int 30, 957-962 (2006).

34. Kőhidai, L., Lajkó, E., Pállinger, É., Csaba, G.: Verification of epigenetic inheritance in a unicellular model system: 
Multigenerational effects of hormonal imprinting. Cell Biol Int 36, 951-959 (2012).

35. Csaba, G., Pállinger, É.: Effect of concanavalin A (Con-A) on the hormone production of the unicellular Tetrahymena and the immune cells of the rat. A comparative study. Cell Biochem Funct 26, 578-581 (2008).

36. Csaba, G.: Is there a hormonal regulation of phagocytosis at unicellular and multicellular levels? A critical review. Acta Microbiol Immunol Hung 64, 357-372 (2017).

37. Darvas, Z., Madarász, B., László, V.: Study of histamine effects on phagocytosis and enzyme secretion of Tetrahymena pyriformis. Acta Biol Hung 50, 325-334 (1999).

38. Castrodad, F. A., Renaud, F. L., Ortiz, J., Phillips, D. M.: Biogenic amines stimulate regeneration of cilia in Tetrahymena thermophila. J Protozool 35, 260-264 (1988).

39. De Jesus, S., Renaud, F. L.: Phagocytosis in Tetrahymena thermophila: Naloxon-reversible inhibition by opiates. Comp Biochem Physiol C 92, 139-142 (1989).

40. Kőhidai, L., Katona, J., Csaba, G.: Effects of steroid hormones on five functional parameters of Tetrahymena: Evolutionary conclusions. Cell Biochem Funct 21, 19-26 (2003).

41. Hegyesi, H., Csabas, G.: Time- and concentration dependence of the growth-promoting activity of insulin and histamine in Tetrahymena. Application of the MTT-method for the determination of cell proliferation in a protozoan model. Cell Biol Int 21, 289-293 (1997).

42. Csaba, G., Németh, G., Vargha, P.: Influence of hormone concentration and time factor on development of receptor memory in a unicellular (Tetrahymena) model system. Comp Biochem Physiol B 73, 357-360 (1982).

43. Calabrese, E. J.: Cell migration/chemotaxis: Biphasic dose responses. Crit Rev Toxicol 31, 615-624 (2001).

44. Calabrese, E. J., Baldwin, L. A.: Defining hormesis. Hum Exp Toxicol 21, 91-97 (2002).

45. Calabrese, E. J.: Opiates: Biphasic dose-response. Crit Rev Toxicol 31, 585-604 (2001).

46. Calabrese, E. J.: 5-Hydroxytriptamine (serotonin): Biphasic dose responses. Crit Rev Toxicol 31, 553-561 (2001).

47. Andersen, M. E., Barton, H. A.: Biological regulation of receptor-hormone complex concentrations in relation to doseresponse assessments for endocrine-active compounds. Toxicol Sci 48, 38-50 (1999).

48. Baker, M. E.: Flavonoids as hormones. A perspective from an analysis of molecular fossils. Adv Exp Med Biol 439, 249-267 (1998).

49. Calabrese, E. J., Baldwin, L. A.: The hormetic dose-response model is more common than the threshold model in toxicology. Toxicol Sci 71, 246-250 (2003).

50. Kovács, P., Nozawa, Y., Csaba, G.: Induction of hormone receptor formation in the unicellular Tetrahymena. Biosci Rep 9, 87-92 (1989).
51. Torday, J. S.: On the evolution of development. Trends Dev Biol 8, 17-37 (2014).

52. Calabrese, E. J., Mattson, M. P.: How does hormesis impact biology, toxicology and medicine? NPJ Aging Mech Dis 3, 13-18 (2017).

53. Christensen, S. T., Guerra, C. F., Awan, A., Wheatley, D. N., Satir, P.: Insulin receptor-like proteins in Tetrahymena thermophila ciliary membranes. Curr Biol 13, R50-R52 (2003).

54. Christensen, S. T.: Insulin rescues the unicellular eukaryote Tetrahymena from dying in a complete synthetic medium. Cell Biol Int 17, 833-837 (1993).

55. Ferreira de Souza, A. M., López, J. A.: Insulin or insulin-like studies on unicellular organisms: A review. Braz Arch Biol Technol 47, 973-981 (2004).

56. Christopher, G. K., Sundermann, C. A.: Isolation and partial characterisation of the insulin binding sites of Tetrahymena pyriformis. Biochem Biophys Res Commun 212, 515-523 (1995).

57. Christipher, G. K., Sundermann, C. A.: Intracellular insulin binding in Tetrahymena pyriformis. Tissue Cell 28, 427-437 (1996).

58. Koch, A. S., Fehér, J., Lukovics, I.: Single model of dynamic receptor pattern generation. Biol Cybernet 32, 125-138 (1979).

59. Offringa, R., Huang, F.: Phosphorilation-dependent trafficking of plasma membrane proteins in animal and plant cells. J Integr Plant Biol 55, 789-808 (2013).

60. Nemere, I., Pietras, R. J., Blackmore, P. F.: Membrane receptors for steroid hormones: Signal transduction and physiological significance. J Cell Biochem 88, 438-445 (2003).

61. Hammes, S. R., Levin, E. R.: Extranuclear steroid receptors: Nature and actions. Endocr Rev 28, 726-741 (2007).

62. Sonneborn, J. S.: The myth and reality of reversal of aging by hormesis. Ann N Y Acad Sci 1057, 165-176 (2005).

63. Sonneborn, J. S.: Mimetics of hormetic agents: Stress-resistance triggers. Dose Response 8, 97-121 (2010).

64. Stebbing, A. R. D.: Stress, health and homeostasis. Marine Pollution Bull 12, 326-329 (1981).

65. Selye, H.: Stress and the general adaptation syndrome. Br Med J 17, 1383-1392 (1950).

66. Csaba, G., Pállinger, É.: A general response to stressors by the unicellular Tetrahymena: Effect of stress on the hormone levels. Cell Biochem Funct 26, 797-800 (2008).

67. Csaba, G.: Hormonal actions in the protozoan stress: A review. Acta Microbiol Immunol Hung 62, 331-339 (2015).

68. Csaba, G., Pállinger, É.: How applicable is the general adaptation syndrome to the unicellular Tetrahymena? Cell Biochem Funct 27, 12-15 (2009).

69. Calabrese, E. J., Baldwin, L. A.: Hormesis: A generalizable and unifying hypothesis. Crit Rev Toxicol 31, 353-424 (2001).

70. Calabrese, E. J.: Hormesis: Changing view of the dose-response, a personal account of the history and current status. Mutat Res 511, 181-189 (2002). 